\title{
Comparative Performance of Biofertilizers on Irrigated Lowland Rice (Oryza sativa L.)
}

\author{
Michelle B. Castillo and Cezar P. Mamaril
}

Philippine Rice Research Institute Los Baños, College 4031 Laguna, Philippines

\begin{abstract}
Biofertilizers have been claimed as an alternative source of nutrients for plants in order to increase yield and reduce the inorganic fertilizer use by $50 \%$. Sixteen trials were undertaken nationwide covering the provinces of Ilocos Norte, Isabela, Nueva Ecija, Laguna, Camarines Sur, Negros Occidental, Leyte, Samar, Bohol, Agusan, and North Cotabato during wet and dry seasons of 2008-2010 to verify the effectiveness of biofertilizers (Bio N, Vital N, BioCon) under lowland or anaerobic ecosystem. The experiment consisted of nine treatments which included control, and biofertilizers applied alone or in combination with inorganic fertilizers either at one-half or full recommended rate. Generally, biofertilizers evaluated showed no positive effect on grain and straw yields of lowland rice and yield components such as plant height, tiller count, number of productive tillers, spikelet count, number of filled grains and unfilled grains, and weight of 100 grains. The positive effect of BioCon, Vital $\mathrm{N}$ and Bio $\mathrm{N}$ on root length at seedling stage may be attributed to the microorganisms producing plant growth hormones which might have enhanced root growth under "dapog" seedbed condition. However, the beneficial effect on root growth was not sustained and reflected in the yield when the seedlings were transplanted in the field. Generally, results show that biofertilizers evaluated were not effective under anaerobic condition.
\end{abstract}

Key Words: anaerobic condition, biofertilizers, microorganisms, root growth

Correspondence: M. B. Castillo. Address: Philippine Rice Research Institute Los Baños, College 4031 Laguna, Philippines. E-mail: mbcastillo@email.philrice.gov.ph.Tel/Fax: 049-501-1917

DOI: 10.32945/atr3412.2012 


\section{INTRODUCTION}

Demand to produce food crops especially rice has increased in recent years to improve the livelihood of farmers and avert food shortage. However, cost of producing rice has been rising due to increasing cost of fertilizers, making it difficult for subsistence farmers to improve their yields and earn more income. These constraints have led farmers to use alternative products including locally produced nutrient sources to improve soil productivity and crop yields at a lower cost.

Numerous commercial products are now introduced in the market. These products are claimed to improve soil productivity, enhance crop growth, and increase yields. Along with commercial organic fertilizers and compost, plant growth-promoting hormones, and other products containing varying types of microorganisms with various functions are in the market. Some of them are called microbial inoculants, microbial activators and biofertilizers but they are generally categorized as "microbial fertilizers". These microbial fertilizers or biofertilizers including Bio N, Vital N, and BioCon are said to contain unique and beneficial strains of soil microorganisms that can fix atmospheric nitrogen, mobilize and release nutrient elements in the soil, produce plant growthpromoting substances that will enhance the growth of the crop, promote faster decomposition of organic materials, serve as biocontrol agent against pest and diseases, keep plants healthy and green even during droughts and pest infestation, and maintain the natural properties of soil. The microorganisms contained in Bio $\mathrm{N}$ are of two strains of bacteria namely, Azospirillum lipoferum and Azospirillum brasilense. The effective microorganism in Vital $\mathrm{N}$ is also Azospirillum while BioCon contains the fungi Trichoderma with the following species: T. parceramosum, $T$. pseudokoningii, and a UV-irradiated strain of T. harzianum (Javier and Brown, 2009).

Advocates of these biofertilizers claim that these materials could replace the nitrogen requirement of plants by about 30-50 percent, reducing the cost of producing crops (Javier and Brown, 2009). Unfortunately, the perception that these materials can be considered as fertilizers is questionable because most of them only provide small amount of nutrients or none at all, unless fortified as in the case of Vital $\mathrm{N}$ which is supplemented with vitamins and minerals required by high yielding crops, including rice. In a study conducted by Perrig et al. (2007), negative results were obtained in terms of siderophore production and phosphate 
solubilization of Azospirillum brasilense. Siderophores are small, highaffinity iron chelating compounds secreted by microorganisms such as bacteria and fungi which are among the strongest soluble $\mathrm{Fe}^{3+}$ binding agents known. Phosphate solubilization refers to hydrolyzing organic and inorganic phosphorus from insoluble compounds.

Proponents of these products have claimed that numerous experiments have been undertaken and have shown positive results. However, many of their claims are either anecdotal or from studies which were not designed properly. Moreover, several of these studies failed to show any additional benefits (Parr et al., 1984). The organisms present in most, if not all, of these biofertilizers have been isolated from soils under aerobic conditions. Therefore, it is likely that these organisms may give beneficial effects only to crops grown under aerobic condition but not in irrigated lowland rice which is grown in anaerobic condition. Flores (2008) conducted a field trial on irrigated rice which showed that the biofertilizers evaluated did not give positive results.

Considering these conflicting claims on these products, a nationwide study was undertaken to verify the effectiveness of some of the biofertilizers under anaerobic condition, with irrigated lowland rice as test crop.

The specific objectives of the study were to (1) determine the comparative performance of three biofertilizers namely, Bio $\mathrm{N}, \mathrm{Vital} \mathrm{N}$ and BioCon under anaerobic condition, (2) determine the soil and environmental conditions that influence if any, the performance of these biofertilizers and (3) generate a general guideline where these biofertilizers can be effectively used to increase crop yields and sustain soil productivity.

\section{MATERIALS AND METHODS}

The study was conducted in collaboration with the Philippine Rice Research Institute PhilRice) branch stations, Department of AgricultureRegional Field Units (DA-RFUs) and State Universities and Colleges) (SUCs). Sixteen field trials were conducted at different locations of the country consisting of seven dry season and nine wet season croppings from 2008-2010. The experimental areas were located at Quiling, Batac, Ilocos Norte; San Mateo, Isabela; Maligaya, Muñoz, Nueva Ecija; Los Baños, Laguna; Masaya, Bay, Laguna; San Jose, Pili, Camarines Sur; Murcia, Negros Occidental; Abuyog, Leyte; San Jorge, Samar; Ilijan Norte, Tubigon, Bohol; 
Gabi, Ubay, Bohol; Basilisa, Agusan; and Bual Norte, Midsayap, North Cotabato..

Soil Characteristics and Rice Varieties Used in the Study

Different varieties of rice such as traditional, selection, certified, and hybrid were used depending on the variety widely grown in the area. Table 1 shows the location and cropping seasons of the biofertilizer trials and the characteristics of the rice varieties used. Soil samples were analyzed at the Analytical Soils Laboratory, University of the Philippines at Los Baños, Laguna (ASL-UPLB). The soil chemical properties were quite variable: $\mathrm{pH}$ ranged from acidic to basic, 5.1 to 8, respectively; organic matter (OM) from very low to high, $0.53 \%$ to $5.68 \%$; total nitrogen $(\mathrm{N})$ content from highly deficient to sufficient, $0.04 \%$ to $0.28 \%$; available phosphorus (P), $0.8-100$ ppm; exchangeable potassium (K), 0.05-1.85 cmol(+) $\mathrm{kg}^{-1}$ soil; sulfatesulfur ( $\mathrm{SO}_{4}-\mathrm{S}$ ), 2-342 ppm; zinc ( $\mathrm{Zn}$ ), 0.03-24 ppm; copper (Cu), 0.2-36 ppm (Table 2). More nutrients were found to be deficient using Minus-one Element Technique (PhilRice, 2008) analysis compared to chemical analysis for irrigated soils. The rates of inorganic fertilizer applied varied among sites and were decided by the collaborators as shown in Table 3.

Each site was characterized by climatic type, soil type consisting of a series name and textural grade. A series is a group of soils that have the same genetic horizons, similar major morphological characteristics, and similar parent material. It comprises of soils having essentially the same general color, structure, consistency, range of relief, natural drainage condition, and other important internal and external characteristics. Lowland rice was planted to different relief or topography from level, undulating, rolling to hilly. In terms of drainage and permeability, not all sites planted to rice were poorly drained, especially those located in sloping areas which were prone to drought and erosion. Soil color, an indicator of soil fertility, varied among sites. Darker soil color (dark brown to black) suggested higher fertility while lighter soil color, lower soil fertility (Table 4).

\section{Experimental Design and Crop Establishment}

There were nine treatments in all sites arranged in RCBD and replicated 3 times. The minimum plot size used was 4 x $5 \mathrm{~m}\left(20 \mathrm{~m}^{2}\right)$. The 


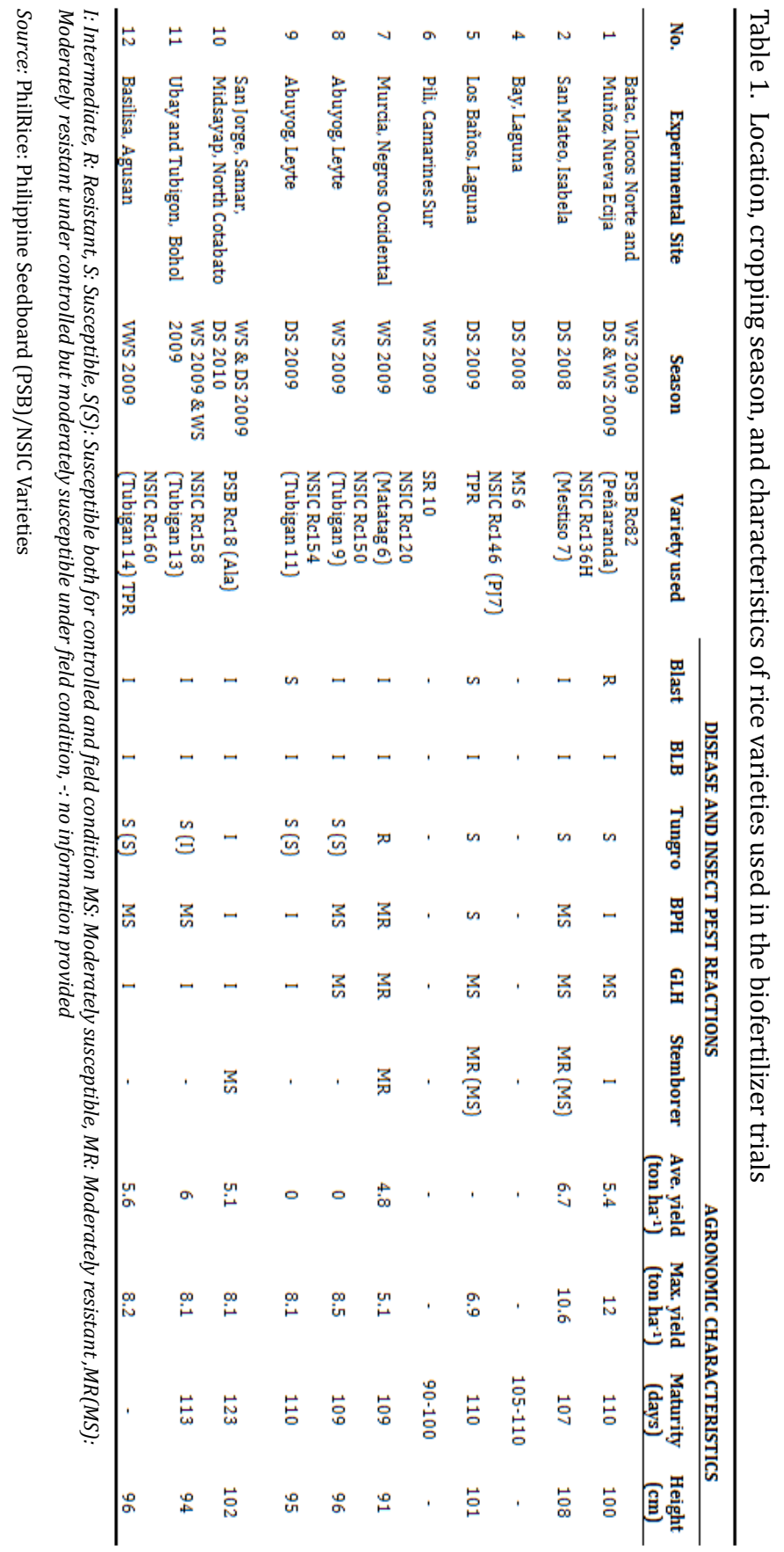




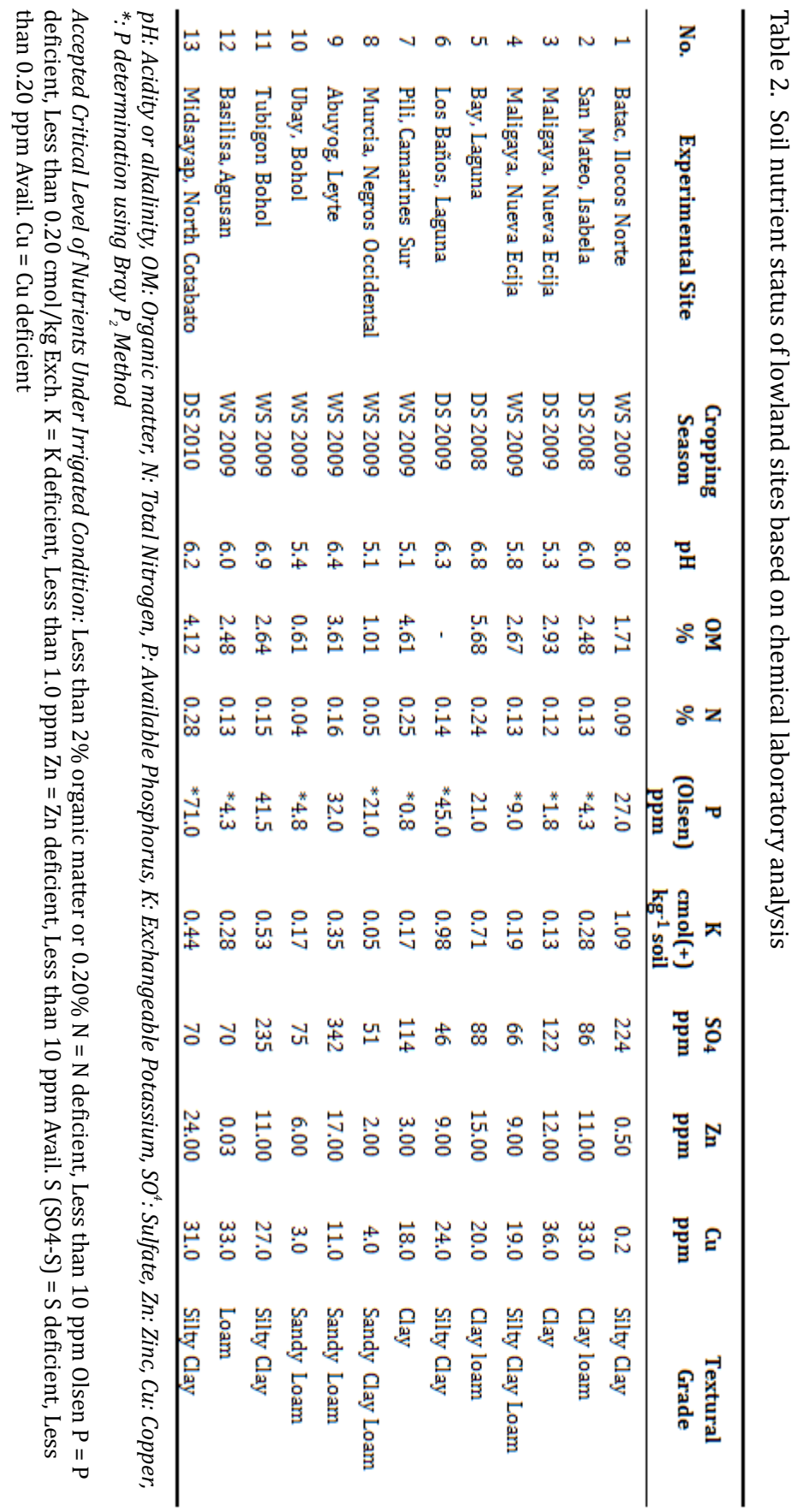




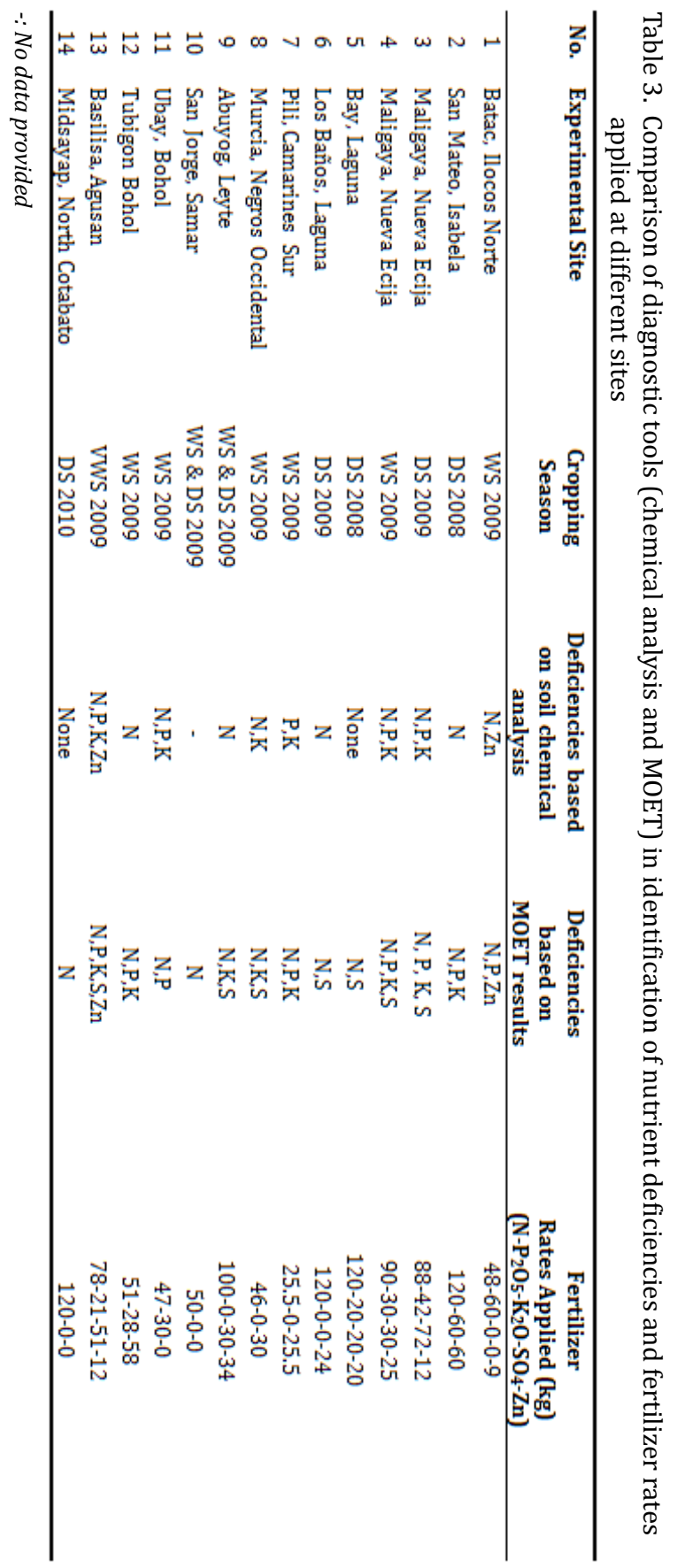




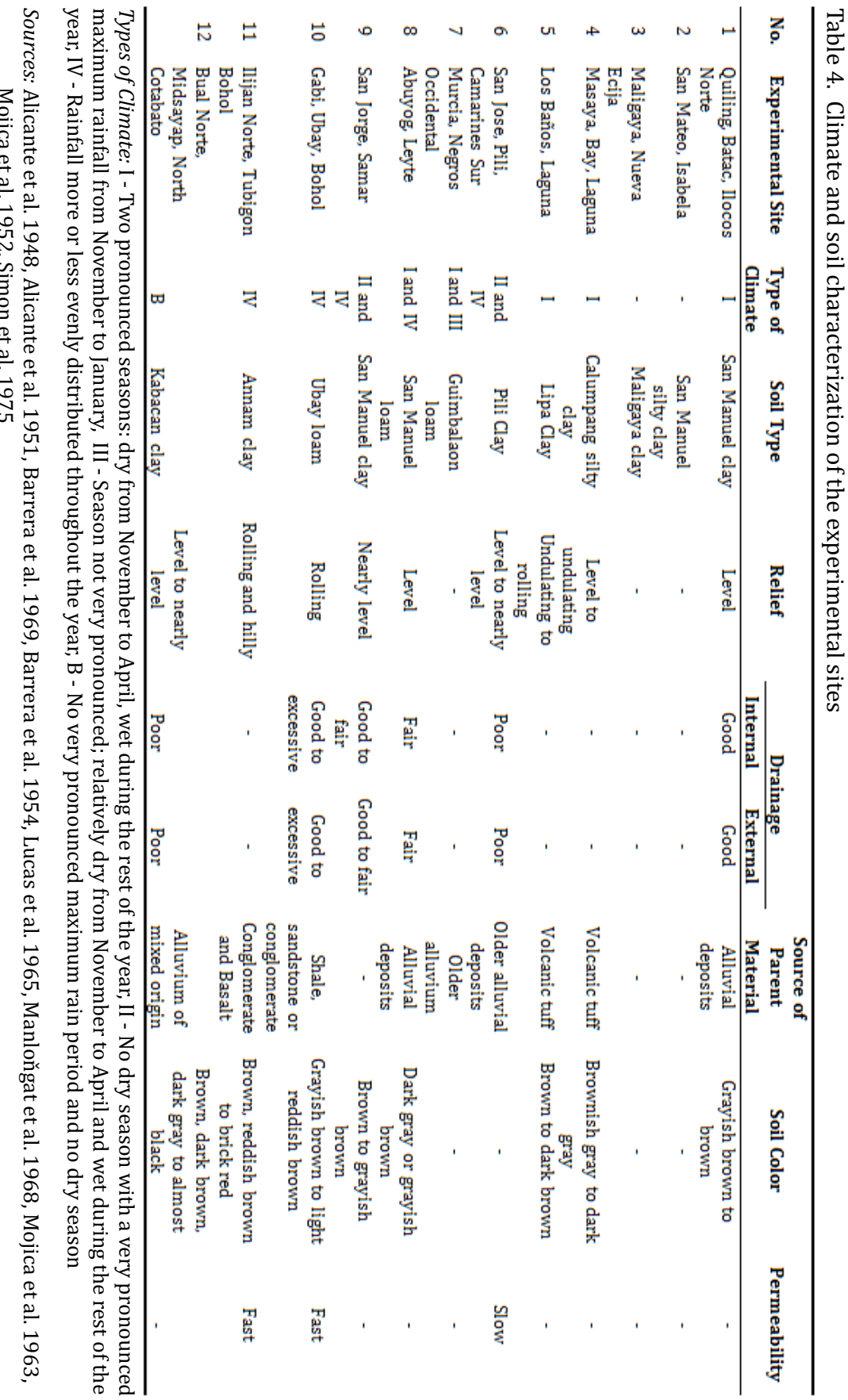


treatments are as follows: (T1) Control, (T2) $1 / 2$ recommended rate of inorganic fertilizer (RR), (T3) Full rate of inorganic fertilizer (FRR), (T4) Bio N only, (T5) Bio N + 1/2 RR, (T6) Vital N only, (T7) Vital N + 1/2 RR, (T8) BioCon only, and (T9) BioCon $+1 / 2$ RR.

The rate and method of application of the biofertilizers were based on the manufacturers' recommendations. The rates of biofertilizers applied for Bio $\mathrm{N}$ were $400 \mathrm{~g} \mathrm{ha}^{-1}$ for $40 \mathrm{~kg}$ inbred rice and $200 \mathrm{~g} \mathrm{ha}^{-1}$ for $20 \mathrm{~kg}$ hybrid rice. During the wet season cropping of lowland rice at Nueva Ecija, $800 \mathrm{~g}$ of Bio N per hectare was applied. For Vital N, $100 \mathrm{~g} \mathrm{ha}^{-1}$ Vital N $^{\mathrm{TM}}$ Green was used. For Biocon, $250 \mathrm{~g} \mathrm{ha}^{-1}$ was applied for $20 \mathrm{~kg}$ hybrid or $40 \mathrm{~kg}$ inbred rice. All the biofertilizers used in the study were purchased directly from the respective manufacturers to insure that the microorganisms in the products were still viable. All the three biofertilizers used were applied through seed coating before incubation period, except for experiments conducted in Bohol where the biofertilizers were applied through soaking of rice roots to dilute solution of biofertilizers for at least $1 \mathrm{~h}$ before transplanting.

\section{Parameters Measured}

Root development of the rice seedlings before transplanting was measured in terms of root length. In "dapog" preparation of seedbed, 10 plants were picked at random from each treatment before transplanting and the average length of roots were recorded.

Grain and straw yields, yield components such as plant height, tiller count, productive tiller count were measured and recorded. Other yield components such as spikelet count, number of filled and unfilled grains, and weight of 100 grains were also measured in some sites. Grain and straw yields were obtained from a harvested area of $3 \times 4 \mathrm{~m}^{2}$ per plot. Grain yield was expressed in tons ha ${ }^{-1}$ at $14 \%$ moisture content while straw yield was expressed in oven-dried weight. Samples consisting of 12 hills randomly selected at the inner borders of each plot were collected at harvest to determine the growth response of various treatments on plant height, number of tillers, and number of productive tillers. Also from the 12 hills, 2 panicles per hill were randomly selected having a total of 24 panicle samples per plot. These samples were measured for number of spikelets, filled, and unfilled grains. The relative weight of grains per plot was determined by weighing 100 filled grains collected from the 24 panicles.. 


\section{Data Analysis}

Statistical analysis using SAS 9 program was done to determine the differences between treatment means at 5\% level of significance by LSD.

\section{RESULTS AND DISCUSSION}

\section{Effects of the Biofertilizers on Root Development}

The microorganisms present in biofertilizers are said to encourage longer, stronger and well-developed root system to explore larger volumes of soil to increase the nutrient absorption capacity of the plant (Javier and Brown, 2009). Moreover, certain soil microorganisms are said to produce growth hormones which induce root growth. Cornejo et al. (2009) reported that wild-type arabidopsis seedlings inoculated with either Trichoderma virens or Trichoderma atroviride showed characteristic auxinrelated phenotypes, including increased biomass production and stimulated lateral root development. When grown under axenic conditions, $T$. virens produced the auxin-related compounds indole-3acetic acid, indole-3-acetaldehyde, and indole-3-ethanol. Perrig et al. (2007), showed an intrinsic capacity of Azospirillum strains Az39 and Cd to produce and release various growth-promoting compounds in chemically defined media through direct physiological mechanisms such as phytohormones (IAA, Z, GA, ABA, ethylene, and growth regulators putrescine, spermine, spermidine) and cadaverine (CAD) production in addition to biological nitrogen fixation.

Results in Table 5 show that in some cases Bio N, Vital N and BioContreated seedlings had significantly longer roots than the untreated plants. BioCon significantly increased the rice root length of MS 6 (Laguna), NSIC Rc154 (Leyte) and NSIC Rc160 (Agusan) over control. Likewise, Bio N also showed a positive effect on root length of NSIC Rc150 (Leyte) and PSB Rc18 (Samar) while Vital N had a significant effect on the root length of PSB Rc82 (Ilocos Norte). However, this effect was only observed at the seedling ("dapog") stage and did not persist throughout the entire growth stage of the crop. This could be due to the change in soil condition from aerobic at seedbed stage to anaerobic when transplanted in the field. A "dapog" seedbed is not totally anaerobic because it makes use of double-layered 


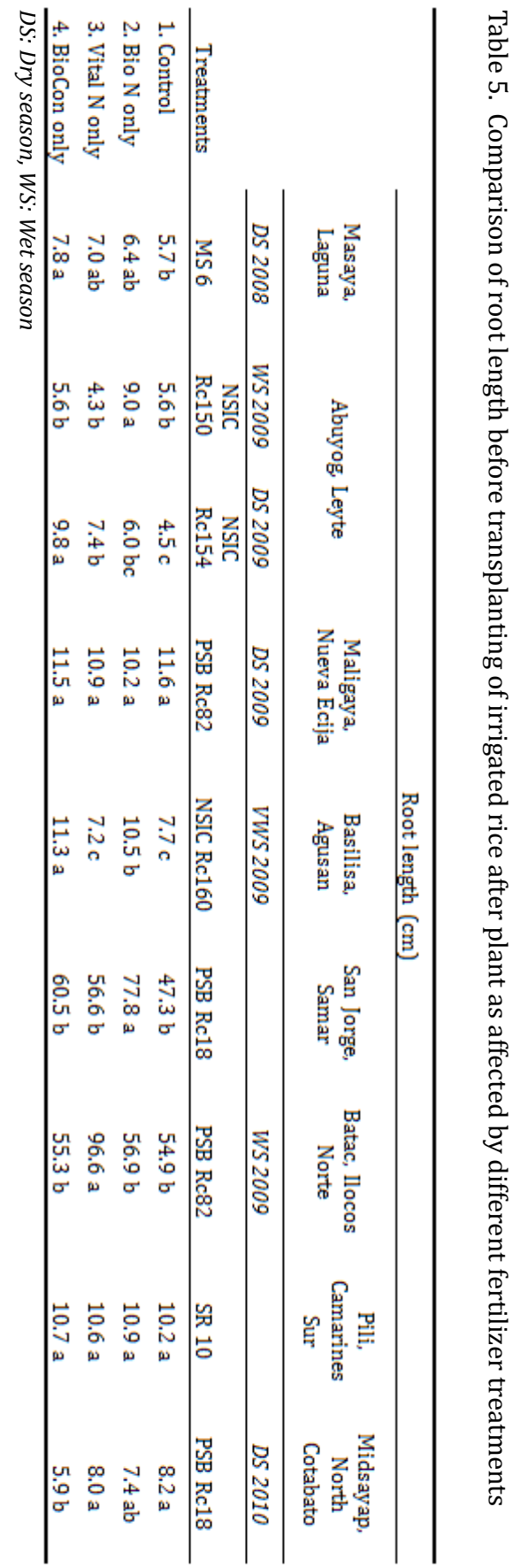


plastic mosquito nets as linings on top of the soil where the seeds are sown or simply a thin layer of soil embedded in plastic or banana stalks. Being aerobic, microorganisms in biofertilizers cannot survive under anaerobic condition.

\section{Grain Yield}

Grain yields at each of the irrigated rice experimental sites are presented in Table 6. In general, the highest yield was obtained from plots receiving the full dose of recommended inorganic fertilizer (FRR). It was followed by the treatments with one-half rate of inorganic fertilizer $(1 / 2$ $\mathrm{RR}$ ) which is not significantly different from the yields obtained by $1 / 2 \mathrm{RR}$ plus biofertilizers. Statistically, control plots had the lowest yield. However, the yield attained by the plots treated with biofertilizer alone did not vary significantly from the control plots. This trend is clearly illustrated in Figure 1 where average yields of all treatments across all sites for wet and dry season croppings are shown. During the dry season, the highest yield was obtained by FRR with $5.6 \mathrm{t} \mathrm{ha}^{-1}$. Yield of biofertilizers only and the control ranged from 3.7-3.8 $\mathrm{t} \mathrm{ha}^{-1}$ while treatments with $1 / 2 \mathrm{RR}$ with or without biofertilizers yielded $5.0 \mathrm{t} \mathrm{ha}^{-1}$. In the wet season, the control and biofertilizers applied alone attained yields from 3.1-3.2 $\mathrm{t} \mathrm{ha}^{-1}$ which were the lowest, while $1 / 2$ RR applied alone or in combination with biofertilizers had 3.8 to $4.0 \mathrm{t} / \mathrm{ha}$. This suggests that the organisms in the biofertilizers tested could not persist under anaerobic or saturated soil conditions, making them unavailable to fix atmospheric $\mathrm{N}$.

While there were sites (Laguna, Camarines Sur, Samar, and Agusan) where the differences were not appreciable between treatments receiving inorganic fertilizers alone as against biofertilizers applied alone or in combination with inorganic fertilizers, it was evident that biofertilizers did not show any positive effect on the grain yield of irrigated rice. There were no significant differences observed between the fertilizer treatments. Some other factors might have affected the yields obtained, thus, it was difficult to draw conclusion from the results. In Laguna, NSIC Rc146 established during 2006 dry season yielded low, 3.1-3.9 tha $^{-1}$, due to heavy rainfall and unfavorable weather conditions that occurred during the vegetative and reproductive stages of the rice plant. Figure 2 shows the amount of rainfall $(\mathrm{mm})$ received by the crop during its growth period. In Agusan, low yields of NSIC Rc160 were also obtained which ranged from 
3.2-4.4 $\mathrm{tha}^{-1}$ due to high amount of rainfall (Figure 3) during the first two months of crop growth which coincided with the vegetative stage of the rice crop. During the reproductive stage, however, there was a significant decrease in rainfall. Although there was a trend that biofertilizers had an effect, this effect was not significant. The crop could have also been underfertilized since only $78 \mathrm{~kg}$ of $\mathrm{N}$ was applied (Table 3 ). This rate was not enough to sustain the need of the crop to achieve maximum yield. The soil was also found to be deficient in zinc but was not amended accordingly, resulting to poor growth of the crop. In Camarines Sur, very low yields of SR 10 (2.3-2.9 $\left.\mathrm{t} \mathrm{ha}^{-1}\right)$ were obtained. Although, the control treatment had significantly lower yield compared to the fertilizer treatments, it cannot be concluded that biofertilizers expressed a positive effect since there were no significant differences observed among all the fertilizer treatments. The low yield may be attributed to low rate of $\mathrm{N}, \mathrm{P}$, and $\mathrm{K}$ added which is only $25.5 \mathrm{~kg} \mathrm{~N}-0 \mathrm{~kg} \mathrm{P}-25.5 \mathrm{~kg} \mathrm{~K}$ (Table 3). Further, the collaborator failed to add $\mathrm{P}$ fertilizer. Based on MOET and chemical analysis, $\mathrm{P}$ was detected to be limiting. In Samar, no clear trend can be drawn from the two cropping seasons of PSB Rc18 as there were no significant differences observed among the fertilizer treatments. The fertilizer recommendation given at 50-0-0 was quite low, thus, the yields of fertilizer treatments were comparable to that of the control. 


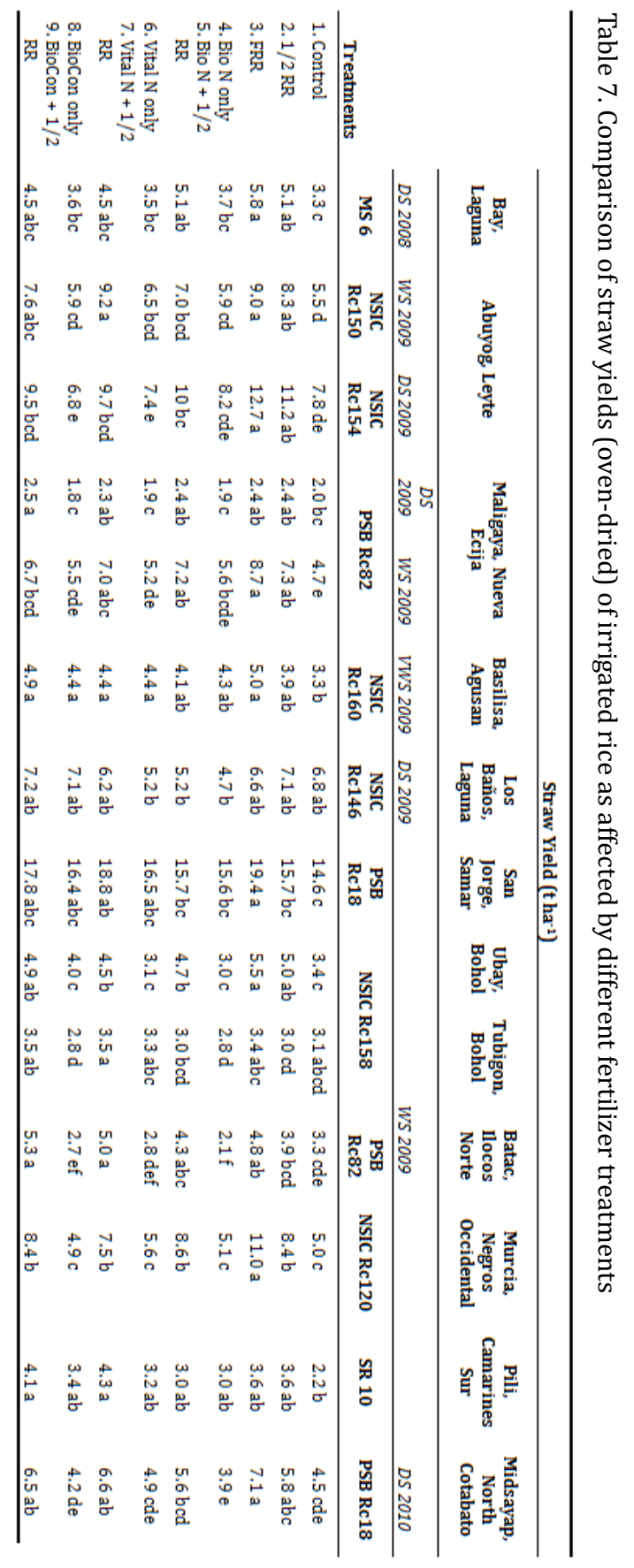




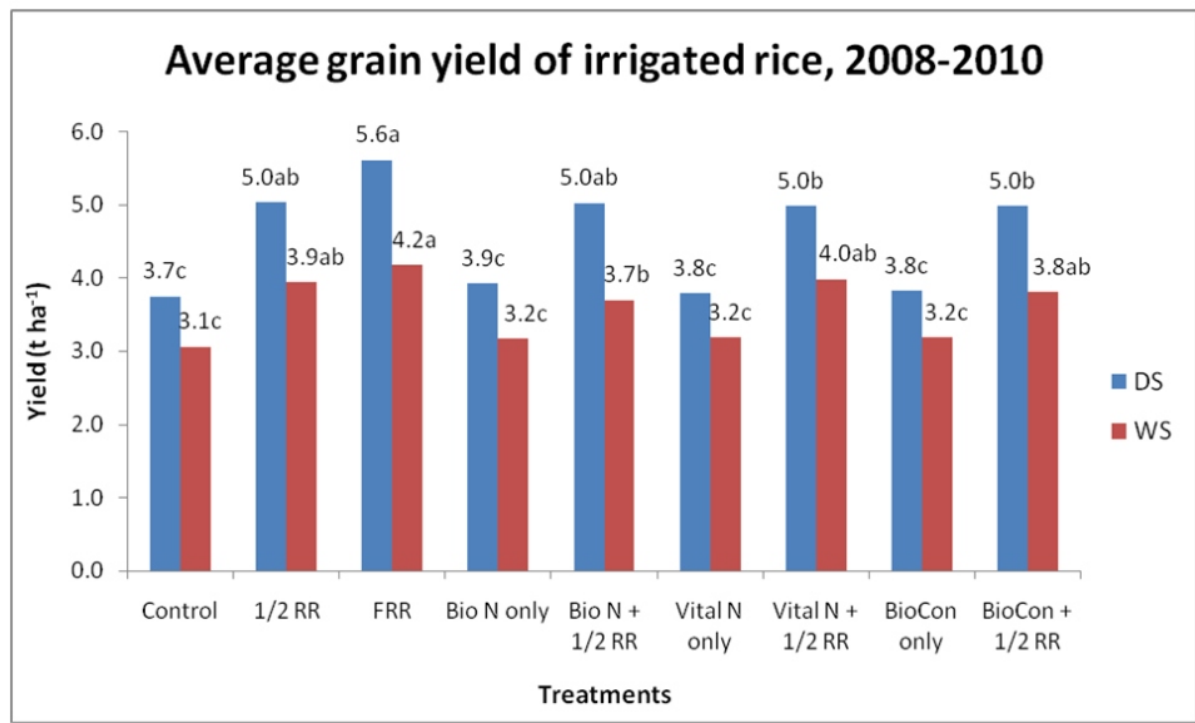

DS: Dry season, WS: Wet season

Figure 1. Average grain yield ( $\left.\mathrm{t} \mathrm{ha}{ }^{-1}\right)$ at $14 \% \mathrm{MC}$ of 16 irrigated rice trials, 7 for DS and 9 for WS, as affected by different biofertilizer treatments

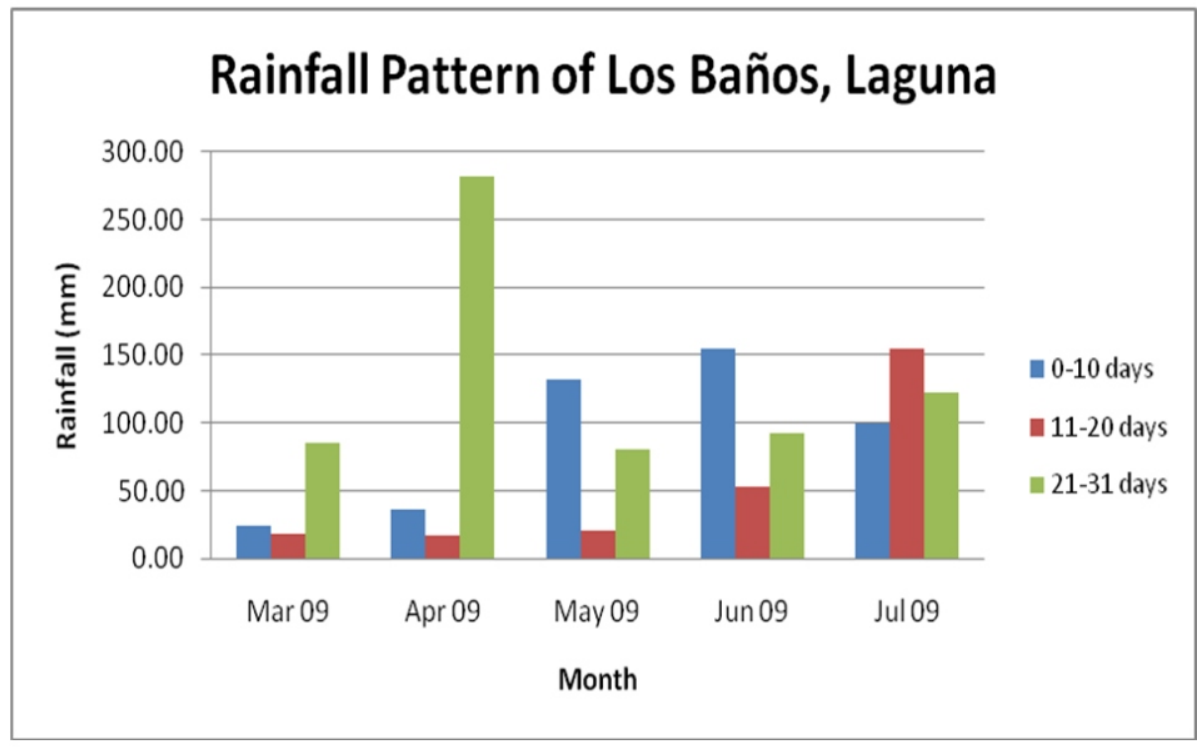

Figure 2. Amount of rainfall (mm) from March to July 2009 at Los Baños, Laguna 


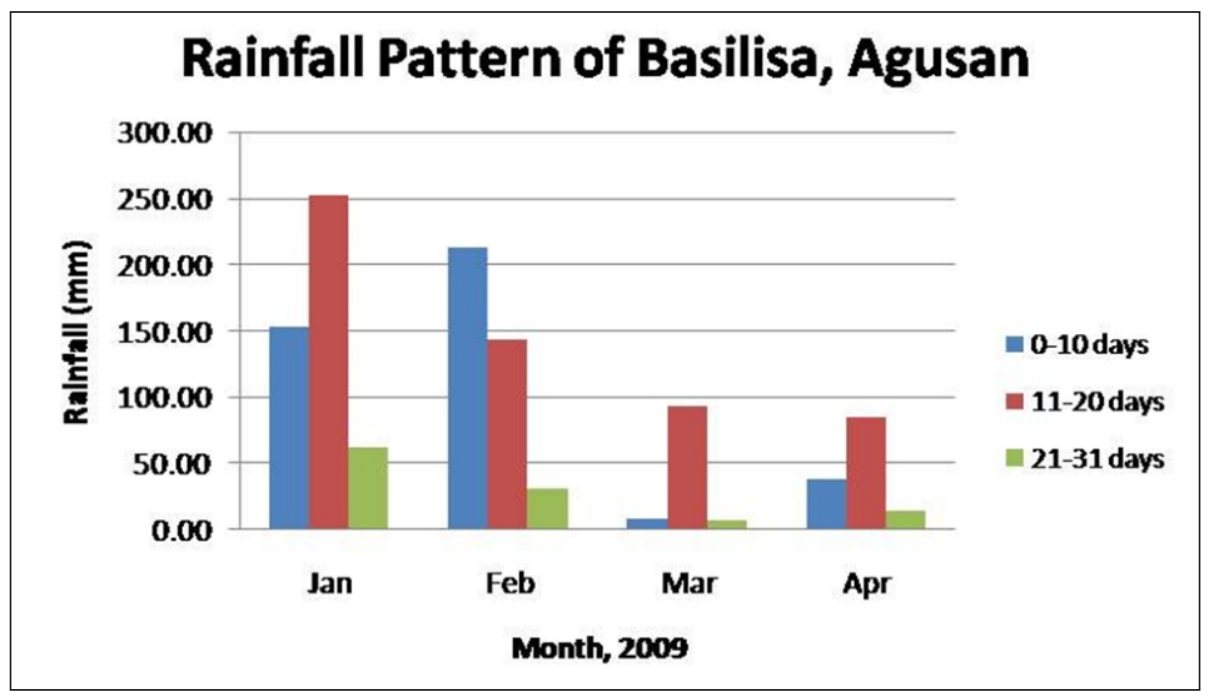

Figure 3. Amount of rainfall (mm) from January to April 2009 at Butuan, Agusan

Straw Yields

In general, the trend of straw yields obtained was similar to those of the grain yields, showing no positive response to biofertilizers (Table 7). The average yield during dry and wet seasons were 4.5-4.9 $\mathrm{t} \mathrm{ha}^{-1}$ and 3.8-4.3 $\mathrm{t}$ $\mathrm{ha}^{-1}$ for control and biofertilizer only treatments, 4.5-6.3 and 5.2-5.7 $\mathrm{t} \mathrm{ha}^{-1}$ for $1 / 2$ RR applied alone or in combination with biofertilizers. FRR treatment produced the highest yield of 6.9 and $6.4 \mathrm{t} \mathrm{ha}^{-1}$, respectively, for dry and wet seasons (Figure 4).

In other experimental sites such as Laguna, Camarines Sur, Samar, Bohol, and Agusan, no significant differences were observed among the treatments.

\section{Yield Components}

Yield components of irrigated rice including plant height, tiller count, number of productive tillers, spikelet count, number of filled grains, number of unfilled grains and weight of 100 grains were also measured. The same trend of results for grain and straw yields was also observed as that of plant height, tiller count and number of productive tillers (Figures 57). Generally, no significant differences were observed among the treatments in terms of spikelet count, number of filled and unfilled grains and weight of 100 grains. 


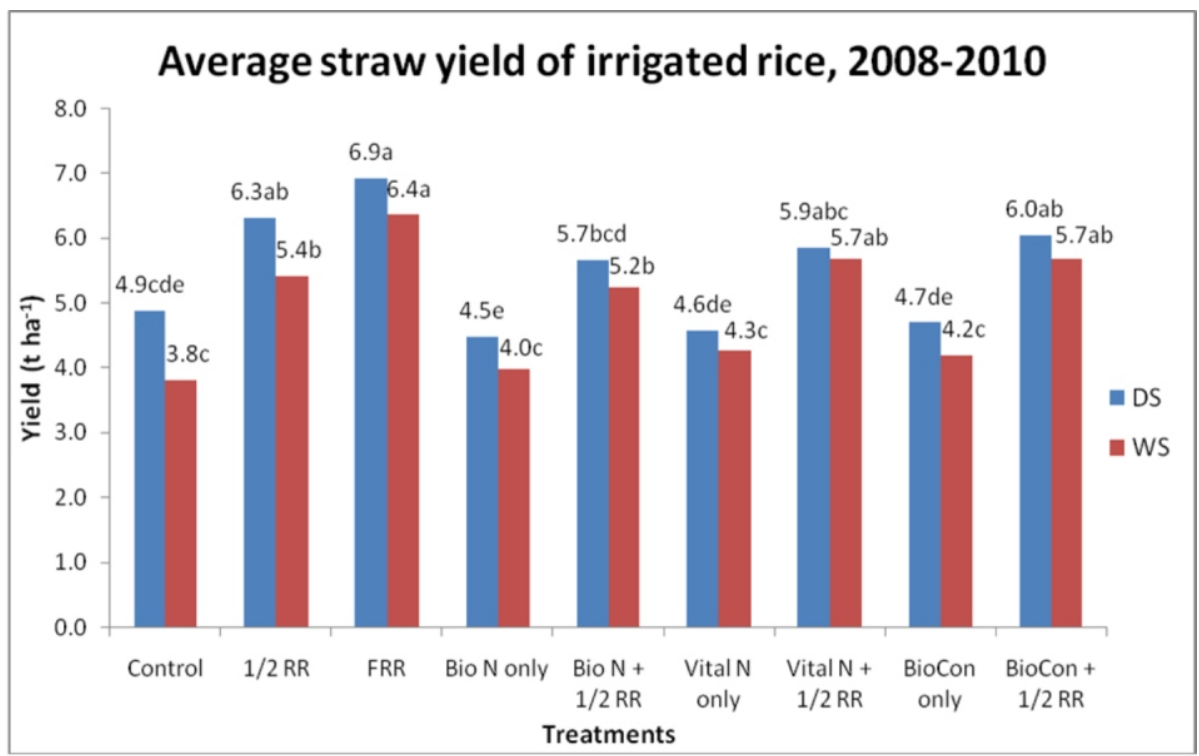

DS: Dry season, WS: Wet season, No data for San Mateo, Isabela (DS 2008) and San Jorge, Samar (DS and WS 2009)

Figure 4. Average straw yields ( $\mathrm{t} \mathrm{ha}^{-1}$ ) of 13 irrigated rice trials, 5 for DS and 8 for WS, as affected by different biofertilizer treatments

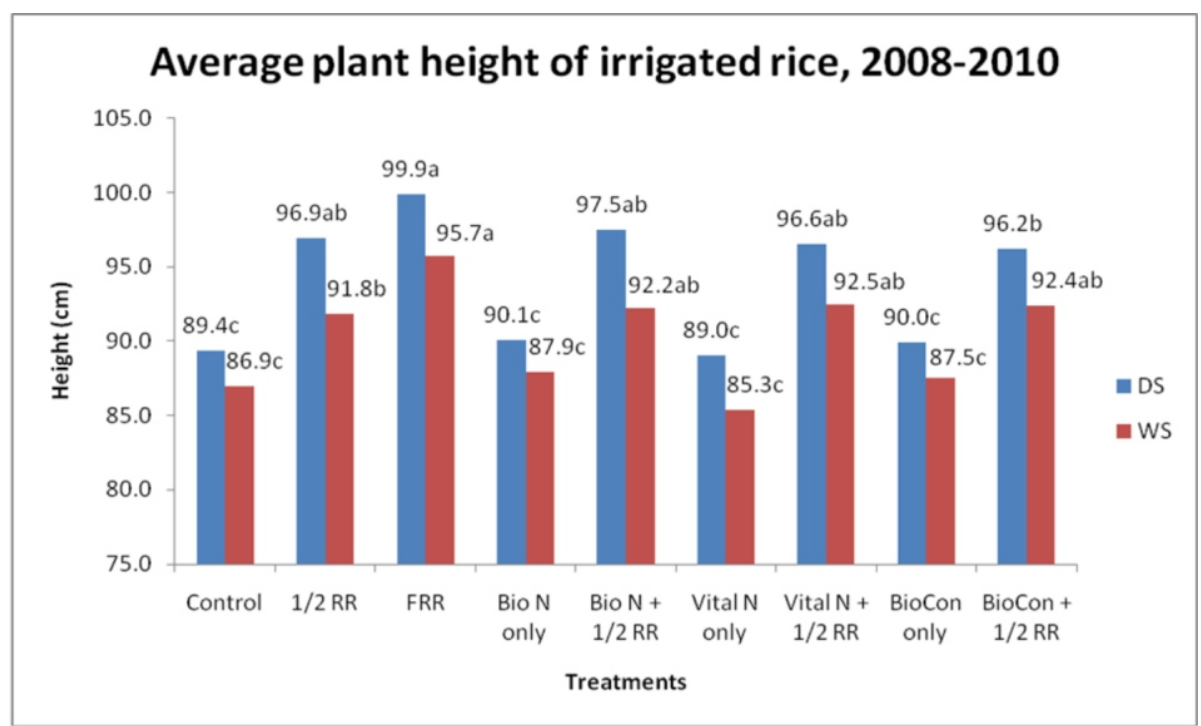

DS: Dry season, WS: Wet season

Figure 5. Average plant height $(\mathrm{cm})$ of 16 irrigated rice trials, 7 for DS and 9 for WS, as affected by different biofertilizer treatments 


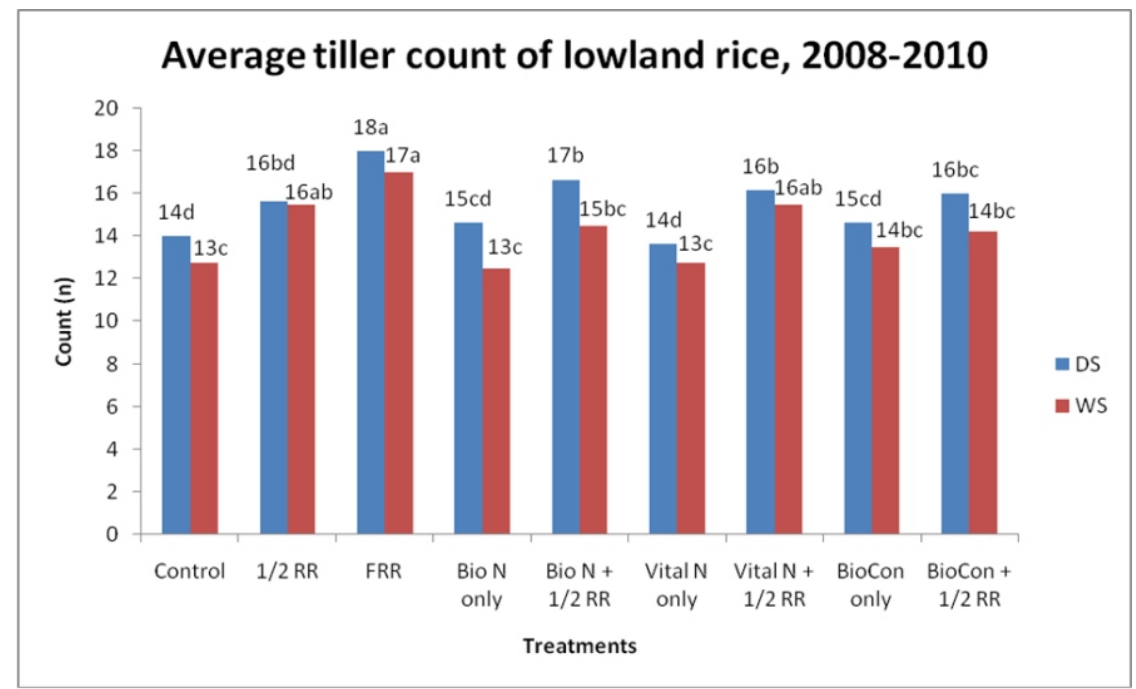

DS: Dry season, WS: Wet season, No data for San Mateo, Isabela (DS 2008), Maligaya, Nueva Ecija (WS 2009), Ubay, Bohol (WS 2009), Tubigon, Bohol (WS 2009), Batac, Ilocos Norte (WS 2009) and Pili, Camarines Sur (WS 2009)

Figure 6. Average tiller count (n) of 10 irrigated rice trials, 6 for DS and 4 for WS, as affected by different biofertilizer treatments

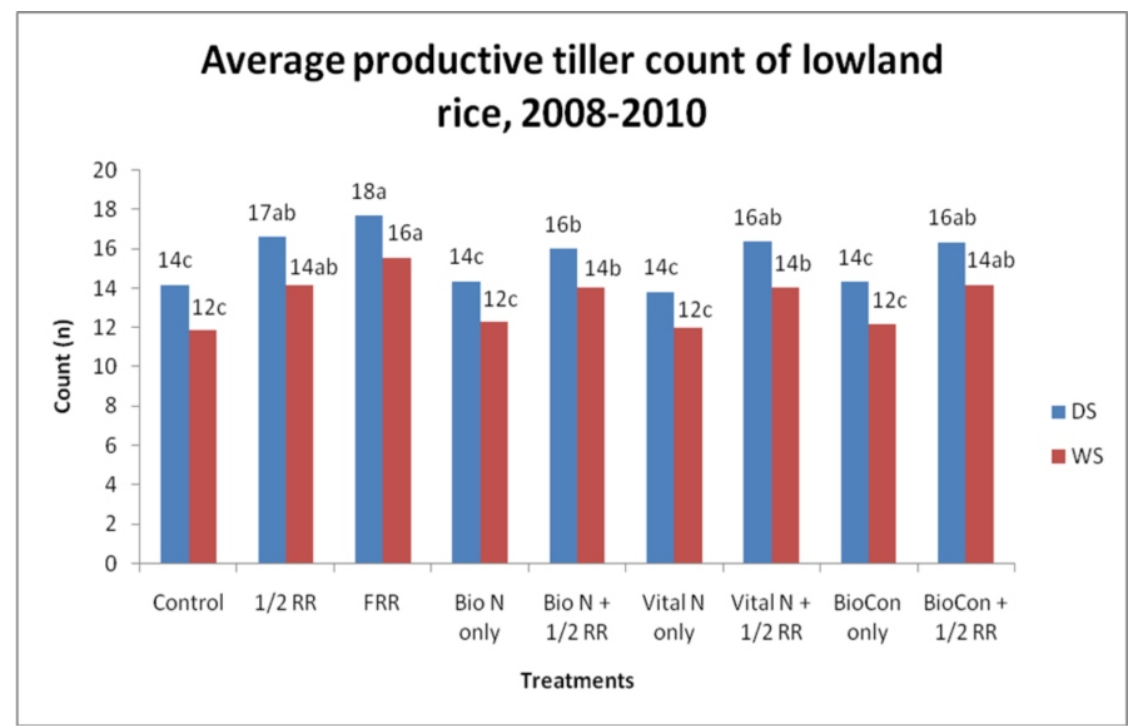

DS: Dry season, WS: Wet season, No data for Abuyog, Leyte (DS and WS 2009) and Basilisa, Agusan (WS 2009)

Figure 7. Average productive tiller count (n) of 13 irrigated rice trials, 6 for DS and 7 for WS, as affected by different biofertilizer treatments 


\section{IMPLICATION OF THE RESULTS}

In determining the efficacy of the three biofertilizers (Bio N, Vital N and BioCon), the treatments of biofertilizers applied alone were compared to the control. If the biofertilizers fix atmospheric nitrogen or stimulate root growth as claimed by the developers of these materials, differences should have been observed in yield compared to the control. Furthermore, if treatments receiving biofertilizers plus $1 / 2$ RR produced yields significantly higher than $1 / 2$ RR alone, then it can be concluded that biofertilizers had positive effect. However, such effect has not been observed. The $1 / 2 \mathrm{RR}$ alone yielded statistically the same as that of the $1 / 2$ RR plus the biofertilizers, suggesting that the biofertilizers had no positive effect.

Generally, grain and straw yields of irrigated rice including yield components, such as plant height, tiller count, number of productive tillers, spikelet count, number of filled grains, number of unfilled grains, and weight of 100 grains showed no positive effects of biofertilizers. The positive effect of BioCon, Vital $\mathrm{N}$ and Bio $\mathrm{N}$ on root length at seedling stage may be attributed to the microorganisms producing plant-growth hormones which might have enhanced root growth under "dapog" seedbed condition. This is probably because the condition in the seedbed is not totally anaerobic. However, upon subjecting to a completely flooded or anaerobic condition after transplanting, most of these microorganisms may not have survived. Thus, the beneficial effect at seedling stage was not sustained throughout the entire growth stage of the lowland rice crop. Otherwise, the beneficial effect of root growth at seedling stage should have been reflected in the yield at harvest. It is therefore evident that biofertilizers are not effective under anaerobic condition.

The term biofertilizer is a misnomer since biofertilizers do not contribute nutrients but merely make nutrients available from other sources such as inorganic fertilizers and indigenous or applied organic matter. Boiero et al. (2007) showed negative results of siderophore production and phosphate solubilization of Azospirillum brasilense in a chemically defined medium.

Biofertilizers are said to contain microorganisms that fix atmospheric nitrogen in the atmosphere. Biological nitrogen fixation requires a lot of energy to fix nitrogen from the atmosphere. Therefore, nitrogen fixation is restricted whenever energy is abundant in the environment. Thus, when the soil is added with readily available nutrient source such as inorganic fertilizer, microorganisms tend to consume the available nitrogen present 
in the soil instead of fixing it from the atmosphere. Deacon (1996) reported that Azospirillum species fix nitrogen when growing in the root zone (rhizosphere) of tropical grasses in field conditions but these bacteria can only make a small contribution to the nitrogen nutrition of the plant, because nitrogen-fixation is an energy-expensive process, and large amounts of organic nutrients are not continuously available to microbes in the rhizosphere.

\section{CONCLUSION}

In general, based from the results of this study, it can be concluded that biofertilizers were not effective in promoting growth and increasing the yield of irrigated rice which is grown in lowland or anaerobic condition. It was also not affected by differences in soil type including topography, drainage, parent material, permeability or climate type nor the chemical nutrient status ( $\mathrm{pH}, \mathrm{OM}, \mathrm{N}, \mathrm{P}, \mathrm{K}, \mathrm{S}, \mathrm{Cu}, \mathrm{Zn})$.

Proponents of biofertilizers should be more stringent in terms of quality control including the shelf-life and proper handling of the product after coming out of the production site up to the time it reaches the farm. It is likely that the viability of the microorganisms could be drastically reduced when the product is subjected to harsh conditions during the intervening period from the manufacturing site to the farm gate. This could be a contributing factor why the biofertilizers evaluated in this study failed to show positive benefits.However, the biofertilizers used in this study were obtained directly from the manufacturing site, thus the question of viability could not be a major cause for the failure of obtaining positive effects of the biofertilizers evaluated.

These microorganisms contained in biofertilizers are claimed to be isolated under aerobic conditions and therefore, work best under conditions where oxygen is not limited. Further research on the use of biofertilizers under upland condition using upland rice, corn or other upland crops using the same experimental design can be done for validation of biofertilizer's efficacy under aerobic condition. 


\section{ACKNOWLEDGEMENT}

The authors wish to thank the Philippine Rice Research Institute (PhilRice) for funding this research project. We also would like to express our sincere gratitude for the researchers, field personnel and farmer cooperators from collaborating agencies for their tireless efforts in the implementation of the study. The collaborators in this research are: Joel Cantoneros, Thelma Rapis, Adelina Aparado and Elvira Torres from Department of Agriculture-Eastern Visayas Integrated Agricultural Research Centers in Leyte and Samar; Evelyn Javier and Corazon Santin from PhilRice Nueva Ecija; Genevieve Nemeño and Mr. Fidel Siclay from PhilRice Agusan; Ning Sosa, Ryan Baldovino and Ferdinand Garcia from PhilRice Isabela; Alvin Palanog from PhilRice Negros; Mel Joy Gapi, Alma Aguinaldo, Elias Bagintok and Cecilio Cases from PhilRice Batac; Concepcion Payapaya and Eugene Cahiles from Agricultural Promotion Center, Bohol; Fe Perlas, Marissa Joy Villano, Jayson Valera, Jobelly Pacis and Presie Nangorog from Central Bicol State University of Agriculture, Camarines Norte; and Kathy Loren Tafere, Joana Rose Vergara, Diosdado Valencia, Hermogenes Bautista and Celedonio Gibas from PhilRice Los Baños.

\section{REFERENCES}

CORNEJO H.C., L.M. RODRIGUEZ, C.C. PENAGOS and J.L. BUCIO. 2009. Trichoderma virens, a plant beneficial fungus, enhances biomass production and promotes lateral root growth through an auxindependent mechanism in arabidopsis. Plant Physiology 149:15791592.

DEACON, J. 1996. The microbial world: The nitrogen cycle and nitrogen fixation. Institute of Cell and Molecular Biology, The University of Edinburgh.

FLORES, A.M. 2008. Effects of different bio-fertilizers and chemical-based fertilizers on the growth and yield of lowland rice. BS Thesis, University of the Philippines, Los Baños, Laguna.

JAVIER P.A. and M.B. Brown. 2009. Bio-fertilizers and bio-pesticides research and development at UPLB. Food and Fertilizer Technology Center for 
the Asian and Pacific Region.

PARR J.F., R.H. Miller and D. Colacicco. 1984. Utilization of organic materials for crop production in developed and developing countries. Organic farming: Current technology and its role in a sustainable agriculture. ASA, CSSA, SSSA, 677 South Segoe Road, Madison, WI 53711.

PERRIG D., M.L. BOIERO, O.A. MASCIARELLI, C. PENNA, O.A. RUIZ, F.D. CASSAN and M.V. LUNA. 2007. Plant-growth-promoting compounds produced by two agronomically important strains of Azospirillum brasilense, and implications for inoculant formulation. Applied Microbiology and Biotechnology 75(5): 1143-1150.

PHILRICE. 2008. Minus-one element technique. Soil nutrition deficiency test made easy. Rice Technology Bulletin, No. 30. Philippine Rice Research Institute. 